\title{
Absence of diurnal variation in visceromotor response to \\ colorectal distention in normal Long Evans rats [version 1;
}

\section{peer review: 3 approved]}

\author{
Sara Botschuijver ${ }^{*}$, Zhumei Yu ${ }^{1,2^{*}}$, Olaf Welting ${ }^{1}$, Cathy Cailotto ${ }^{1}$, \\ Andries Kalsbeek ${ }^{3}$, Rene van den Wijngaard ${ }^{1}$ \\ ${ }^{1}$ Department of Gastroenterology and Hepatology, Tytgat Institute for Liver and Intestinal research, Academic Medical Center, \\ Amsterdam, Amsterdam, The Netherlands \\ 2Department of Neurobiology, Tongji Medical College, HUST, Wuhan, China \\ ${ }^{3}$ Department of Endocrinology and Metabolism, Academic Medical Center, University of Amsterdam, Amsterdam, The Netherlands \\ ${ }^{*}$ Equal contributors
}

V1 First published: 22 Jan 2016, 5:98

https://doi.org/10.12688/f1000research.7238.1

Latest published: 22 Jan 2016, 5:98

https://doi.org/10.12688/f1000research.7238.1

\section{Abstract}

Background: Enhanced colorectal sensitivity (i.e. visceral hypersensitivity) is thought to be a pathophysiological mechanism in irritable bowel syndrome (IBS). In healthy men a circadian variation in rectal perception to colonic distention was described. Disturbed day and night rhythms, which occur in shift work and trans meridian flights, are associated with the prevalence of IBS. This raises the question whether disruptions of circadian control are responsible for the observed pathology in IBS. Prior to investigating altered rhythmicity in relation to visceral hypersensitivity in a rat model for IBS, it is relevant to establish whether normal rats display circadian variation similar to healthy men.

Methodology and findings: In rodents colorectal distension leads to reproducible contractions of abdominal musculature. We used quantification of this so called visceromotor response (VMR) by electromyography (EMG) to assess visceral sensitivity in rats. We assessed the VMR in normal male Long Evans rats at different time points of the light/dark cycle. Although a control experiment with male maternal separated rats confirmed that intentionally inflicted (i.e. stress induced) changes in VMR can be detected, normal male Long Evans rats showed no variation in VMR along the light/dark cycle in response to colorectal distension.

Conclusions: In the absence of a daily rhythm of colorectal sensitivity in normal control rats it is not possible to investigate possible aberrancies in our rat model for IBS.

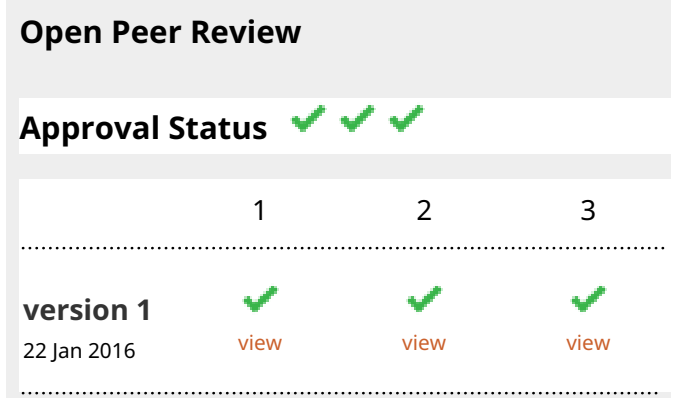

1. David Grundy, University of Sheffield, Sheffield, UK

2. Eamonn Quigley (ID), The Methodist Hospital, Weill Cornell Medical College, Houston, USA

3. Siobhain O'Mahony, University College Cork, Cork, Ireland

Any reports and responses or comments on the article can be found at the end of the article. 


\section{Keywords}

Circadian, clock, diurnal, irritable bowel syndrome, IBS, perception, rat, visceral perception

\section{Corresponding author: Rene van den Wijngaard (R.vandenWijngaard@AMC.UVA.NL)}

Competing interests: No competing interests were disclosed.

Grant information: SB was supported by The Netherlands Organization for Health Research and Development (ZonMW), grant number 40-42600-98-071 (grant program 'Meer Kennis met Minder Dieren' aiming to publish solid negative data in animal research). ZY was sponsored by the China Exchange Programme of The Royal Netherlands Academy of Arts and Sciences (KNAW, project number 11CDDP005). OW was funded by a grant from the Dutch Organization for Scientific Research (NWO-VIDI).

The funders had no role in study design, data collection and analysis, decision to publish, or preparation of the manuscript.

Copyright: ( $) 2016$ Botschuijver S et al. This is an open access article distributed under the terms of the Creative Commons Attribution License, which permits unrestricted use, distribution, and reproduction in any medium, provided the original work is properly cited. Data associated with the article are available under the terms of the Creative Commons Zero "No rights reserved" data waiver (CC0 1.0 Public domain dedication).

How to cite this article: Botschuijver S, Yu Z, Welting $\mathrm{O}$ et al. Absence of diurnal variation in visceromotor response to colorectal distention in normal Long Evans rats [version 1; peer review: 3 approved] F1000Research 2016, 5:98 https://doi.org/10.12688/f1000research.7238.1

First published: 22 Jan 2016, 5:98 https://doi.org/10.12688/f1000research.7238.1 


\section{Introduction}

Irritable bowel syndrome (IBS) is one of the most common functional gastrointestinal disorders and abdominal pain is the key contributing factor ${ }^{1}$. Up to $50 \%$ of patients have increased perception of gastrointestinal stimuli and this so called visceral hypersensitivity (assessed by rectal balloon distension) is considered a major pathophysiological mechanism ${ }^{2}$. Circadian variation in perception of rectal distention was described in healthy male volunteers ${ }^{3}$. The observed rhythmicity may relate to the autonomic nervous system being under the regime of the circadian clock $^{4}$. This raises the question whether visceral hypersensitivity in IBS can be explained by disrupted circadian control of the autonomic nervous system. A subtle increase in sympathetic and decrease in parasympathetic nervous activity was observed in patients ${ }^{5}$ and complaints are known to show a daily variation, with higher pain scores early in the morning ${ }^{6}$. In addition, a disturbed day/night rhythm, which occurs in shift work and after transmeridian flights, is associated with the prevalence of IBS ${ }^{7,8}$. We wanted to investigate whether disrupted circadian control of the autonomic nervous system can explain post-stress hypersensitivity to colorectal distension observed in a rat model of IBS (i.e. the well validated maternal separation model ${ }^{9,10}$ ). However, before investigating possible aberrancies it was essential to confirm, in our experimental setting, earlier reported circadian variation of perception in normal 'non-IBS' rats ${ }^{11}$. In rodents, colorectal balloon distension leads to reproducible contractions of abdominal musculature (the visceromotor response [VMR]). The electromyographical (EMG) quantification of this response is often used to assess visceral sensitivity and changes thereof in rodents $^{10,12}$. We used VMR quantification by EMG to assess possible circadian variation of visceral perception in Long Evans rats.

\section{Methods}

\section{Animal ethics}

All research was conducted in accordance with the institutional guidelines and approved by the Animal Ethical Committee of the AMC/University of Amsterdam (reference protocol number 100998).

\section{Rats}

25 Long Evans rats (Harlan, Horst, Netherlands) were bred and housed at the animal facility of the Academic Medical Center (Amsterdam, Netherlands). Rats were housed in a $12 \mathrm{~h}$ light/ $12 \mathrm{~h}$ dark cycle (lights on at 07:00) under a constant temperature of $20 \pm 2 \mathrm{C}^{\circ}$ and were provided with food and water ad libitum.

\section{Measurement of the visceromotor response to colonic distension}

To avoid restraint stress during measurements, we previously validated and used radio-telemetry for assessing the VMR in freely moving rats ${ }^{12}$. The same methodology was used in the current investigations. In short, at a minimum age of 4 months, a telemetric transmitter with its two connected EMG electrodes (Physiotel Implant TA10AE-F20; Data Sciences International, St Paul, MN, USA) was implanted in the right side of the abdominal cavity. The electrodes were sutured in parallel into the left external abdominal oblique muscle $10 \mathrm{~mm}$ apart and $10 \mathrm{~mm}$ to the midline incision. After a postoperative recovery period of at least 10 days, the animals were subjected to colonic distention protocols. For this purpose, a latex balloon (Ultracover size 8F; International Medical Products BV, Zutphen, Netherlands) catheter was inserted $1 \mathrm{~cm}$ into the colon and fixed to the base of the tail under a short isoflurane anesthesia. After a $20 \mathrm{~min}$ recovery period, animals were placed in a macrolon cage (exact size of the receiver) that was positioned on top of the receiver. The receiver was linked to a Biopac MP100 data acquisition system (Biopac Systems Inc., Santa Barbara, CA, USA) and a personal computer via a raw data analog converter (Data Sciences International). Data were acquired with AcqKnowledge software (version 3.2.6, Biopac Systems Inc.). Colonic distention was achieved by slow manual inflation $(5 \mathrm{~s})$ of graded volumes of water $(1.0,1.5$ and $2.0 \mathrm{~mL})$ into the balloon using a syringe. Length and diameter of the balloon during a $2 \mathrm{~mL}$ maximum volume distention were 18 and $15 \mathrm{~mm}$, respectively. All distensions lasted for $20 \mathrm{~s}$ and were separated by an $80 \mathrm{~s}$ rest in order to allow the EMG signal to return to baseline.

\section{Diurnal measurements of VMR to distension in normal nonhandled rats}

Our earlier investigations indicated that repetitive distension sessions in normal male Long Evans rats (carried out at 09:00 on different days during a one month time period) result in equal VMR data $^{13}$. Thus, inter distension-session interference is ruled out when repetitive measurements are carried out on different days. In the present investigations the VMR to colonic distension of 16 male nonhandled rats was measured at four different time points; 04:00, 08:00, 16:00, and 20:00. Experimental bias was avoided by stratifying rats into 4 equal groups: one group of four rats started sessions at 04:00, followed by 08:00, 16:00 and 20:00, another group started at 08:00 followed by 16:00, 20:00 and 04:00 etc. There was a minimum of 24 hours between distension sessions and all sessions within one group were completed within 15 days. To ascertain proper timing, not more than four animals per session were measured. During dark regime measurements, experiments were carried out under dim red light conditions and the experimental room was devoid of the regular tube light of the housing facility.

\section{Stress induced visceral hypersensitivity in maternal separated rats}

In adult male maternal separated Long Evans rats, acute stress is known to induce enhanced sensitivity to colorectal distension ${ }^{12-15}$. To assure that, when present, our methodology can accurately assess changes in VMR to colorectal distension, comparison of pre- and post-stress measurements in maternal separated rats was used as a positive control. Maternal separation was accomplished by placing the dams into another cage in another room for 180 minutes per day from postnatal day 2 to 14 . During separation, cages were placed on a heating pad $\left(30-34^{\circ} \mathrm{C}\right)$ to help pups regulate normal body temperature. Pups were weaned on day 22 and subsequently raised in pairs of two until the age of 4 months when they were subjected to the experimental protocol. Earlier, we showed that post-stress hypersensitivity to distension will last for at least one month ${ }^{13}$. In line with the multiple distension sessions performed in the diurnal experiment (all four sessions carried out within a maximum timeframe of 15 days), colorectal distensions and concurrent EMG measurements were carried out pre- and 15 days post-stress. Rats were subjected to one single stress session by placing individual rats on top of a pedestal $(8 \cdot 8 \cdot 10 \mathrm{~cm})$ attached to the bottom of 
a plexiglass tank $(25 \cdot 25 \cdot 45 \mathrm{~cm})$. The tank was filled with fresh tap water at room temperature $\left(21^{\circ} \mathrm{C}\right)$ within $1 \mathrm{~cm}$ of the top of the pedestal and rats remained in the tank for 1 hour.

\section{Data analysis and statistics}

Data analysis was carried out similar to our earlier publications ${ }^{12,14,15}$. Each $20 \mathrm{~s}$ distension period and its preceding $20 \mathrm{~s}$ of baseline recording were extracted from the original raw EMG data file. After correction for movement and breathing, data were rectified and integrated. Absolute data sets were then obtained by subtracting the $20 \mathrm{~s}$ baseline recording from the $20 \mathrm{~s}$ distension result. Normalized data sets were then calculated from the absolute data by setting, in case of diurnal measurements, the $2 \mathrm{~mL}$ value of the 04:00 distension session, and in case of maternal separated rats the $2 \mathrm{~mL}$ value of the pre-stress distension session, at $100 \%$. Area under the curve (AUC) of relative responses was calculated for individual rats and used to show possible changes in visceromotor response within groups. Relative response data were also used to evaluate possible changes on a per volume basis.
Statistical analyses were performed using GraphPad Prism version 5.00 for Windows (GraphPad Software, San Diego, CA, USA). Diurnal variation in VMR (AUC as well as per volume results of the relative response) were evaluated by Friedman's test. Pre- vs post-water avoidance data (AUC and per volume results of the relative response) of maternal separated rats were analysed by using Wilcoxon signed ranks test. All results are displayed as mean \pm SEM and $P<0.05$ was considered significant.

\section{Results}

Dataset 1. Excel datasheet showing raw EMG data acquired during colonic distensions

http://dx.doi.org/10.5256/f1000research.7238.d111689

Also shown are the normalized datasets used to compile Figure and Figure 2 depicting diurnal pattern of visceromotor response to distension in normal rats and the control experiment showing maternally separated rats before and after water avoidance stress.

B
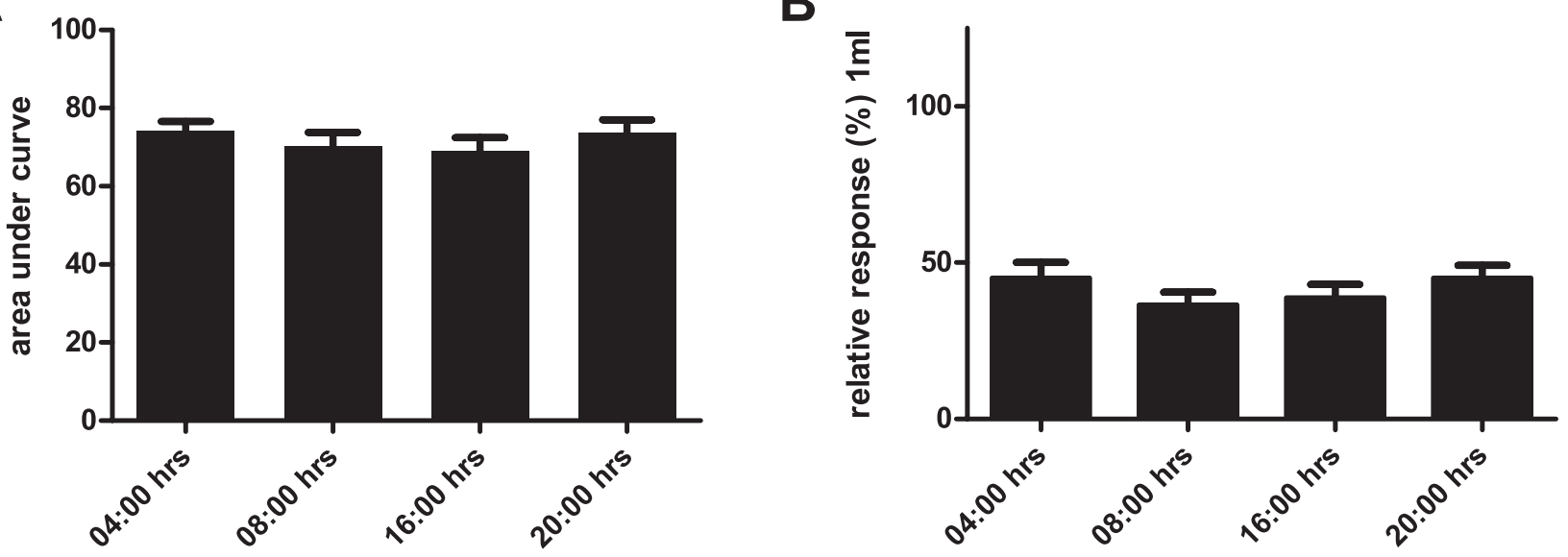

C

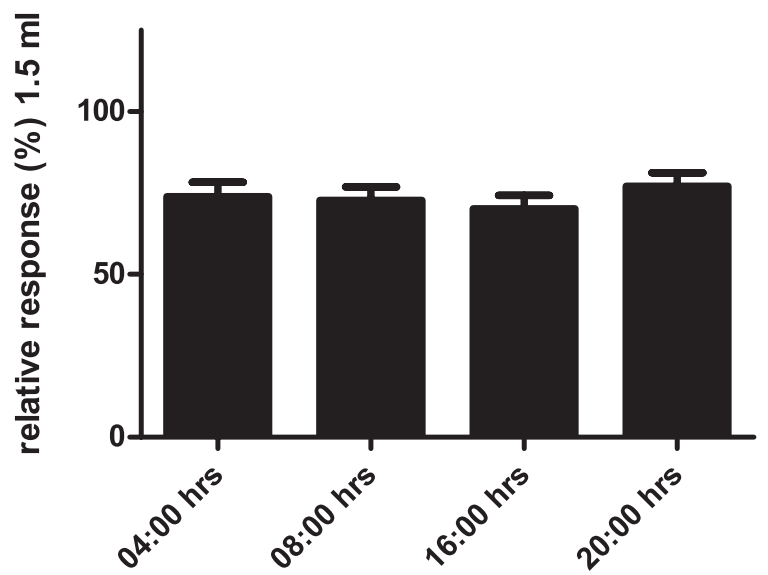

D

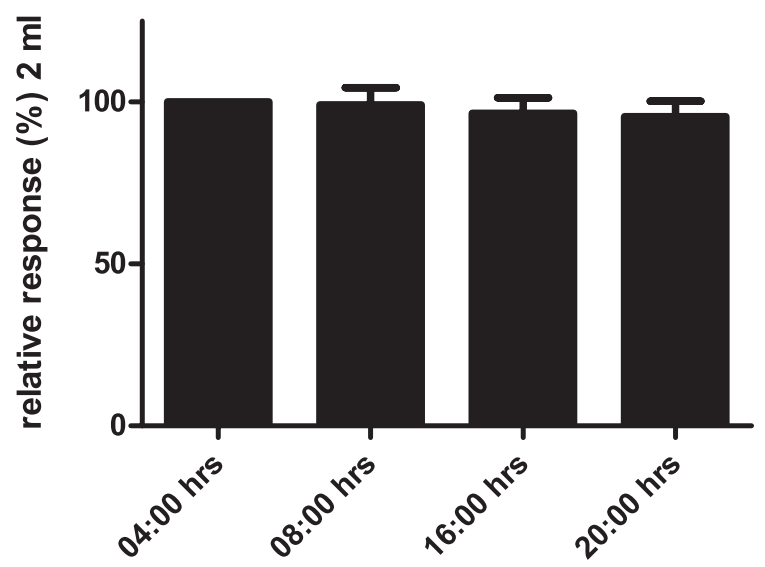

Figure 1. Diurnal pattern of VMR to distension in normal male Long Evans rats. Mean area under the curve \pm SEM of the relative responses at 04:00, 08:00, 16:00 and 20:00 hrs in $n=16$ normal male Long Evans rats (Friedman's test $P=0.69)(\mathbf{A})$. Using the same data set but now depicting per volume relative responses on different time points (Friedman's test $P=0.55,0.95$ and 0.93 ; $\mathbf{B}, \mathbf{C}$ and $\mathbf{D}$ respectively). 
A
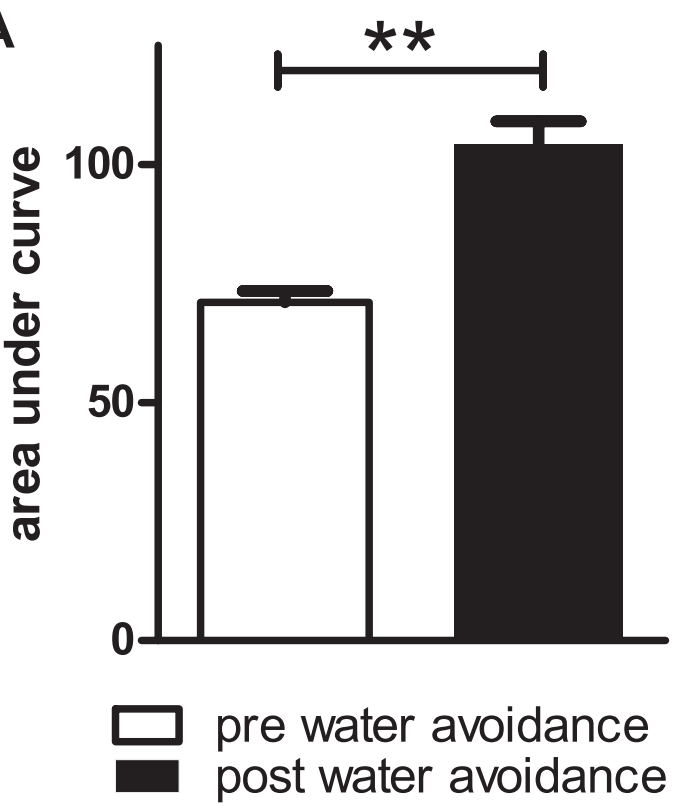

B

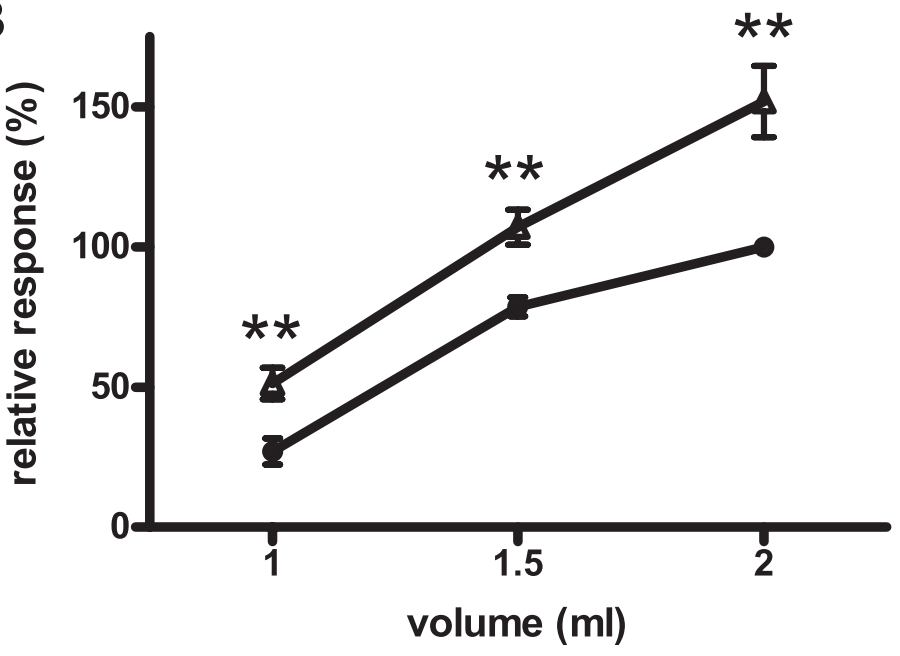

- pre water avoidance $\leftarrow$ post water avoidance

Figure 2. Pre- vs post-water avoidance VMR to distension in maternal separated male Long Evans rats. Pre- vs post-water avoidance area under the curve \pm SEM of the relative response to distension $(\mathbf{A})$. Same data set now depicted for per volume responses; increased post-stress response to distension at all 3 distension volumes $(\mathbf{B})$. $n=9$, Wilcoxon's test ${ }^{\star *} P<0.01$.

\section{Diurnal VMR to distension in normal male rats}

We assessed the VMR to distension in normal male Long Evans rats along four different time points of the light/dark cycle. Due to battery failure of its telemetric transmitter one animal could not be evaluated. Comparing area under the curve (AUC) of the relative response at the four time points we observed no daily variation (Figure 1A, $\mathrm{n}=15$, Friedman's test $P=0.69$ ). Since the AUC reflects the mean visceral sensitivity over a range of distension volumes, more subtle daily variations are perhaps better reflected when comparing results on a per volume basis. However, no significant differences were observed when comparing results for 1.0, 1.5 and $2.0 \mathrm{~mL}$ on the different time points (Figure 1B-D, Friedman's test $P=0.55,0.95$ and 0.93 respectively).

\section{Pre- vs post-water avoidance VMR to distension in maternal separated rats}

We next performed a control experiment to ascertain that, when present, our methodology was capable of detecting changes in VMR to distension. Similar to our earlier publications, male Long Evans pups were subjected to the maternal separation protocol and exposed to a one hour water avoidance stress at adult age. For reasons detailed in the methods section, distension sessions in the 'diurnal variation assessment' were carried out within a 15 day timeframe. Therefore, pre-water avoidance measurements in the maternal separation experiment were compared to measurements obtained 15 days post-water avoidance. Rats showed a significant post-stress increase in VMR to distension (Figure 2A, mean AUC \pm SEM; $71.2 \pm 2.4$ vs $104 \pm 4.8$, Wilcoxon's test $P=0.004$, pre- vs post-stress respectively). Figure $2 \mathrm{~B}$ depicts the same data but now evaluated on a per volume basis; pre- vs post-water avoidance comparisons indicated significantly increased response to distension at all 3 distension volumes $(P<0.01)$.

\section{Discussion}

Unlike earlier observations in male Lewis rats ${ }^{11}$, our results indicate that male Long Evans rats do not experience daily variation of sensitivity to distension. Although EMG recordings of abdominal contractions were used as read-out in both rat studies, some differences in colonic distension methodology (volume vs isobaric distensions) are apparent and may explain the observed discrepancy. For our EMG recordings we used a radio-telemetry technique that we evaluated earlier, it allows for measurements in freely moving and non-fasted rats ${ }^{12}$. Performing measurements in freely moving rats lowers the amount of stress that is usually encountered when rats are restrained ${ }^{16}$ as is often the case during isobaric distensions. This is relevant because stress is a trigger for visceral hypersensitivity in patients as well as rats ${ }^{17,18}$. The downside of our approach is that freely moving rats easily expel from the colon the balloons suitable for isobaric distensions ${ }^{12}$. Thus, we performed less favored volume distensions which enable the use of balloons that will stay fit in the colon during rat movement, but cannot account for possible variations of colonic tone. The latter is an important difference with the methodology used by Gschossmann et al. who used barostat technology to perform isobaric distensions ${ }^{11}$. However, these results were obtained in Lewis rats that had to be subjected to an $18-24 \mathrm{~h}$ fasting period prior to- as well as restraint during 
distensions; both fasting and restraint are known triggers for stress $^{16,19}$. Moreover, compared to other rat strains Lewis rats are more stress sensitive and exhibit aberrant visceral pain sensitivity ${ }^{20}$. Especially because time of day of stress exposure is known to affect response levels ${ }^{21}$, it can be speculated that earlier observations in Lewis rats reflected methodology-induced rhythmicity of stress responses and accompanying changes in visceral sensitivity rather than diurnal variation in visceral sensitivity as such. Despite precautions taken, our own experiments also may have suffered from unforeseen/unnoticed methodology-induced bias affecting clock regulated mechanisms including diurnal sensitivity changes. Such bias could have been ruled out by establishing normal circadian release of an example hormone or the use of other readouts under the control of the biological clock. This however, would not have changed the end conclusion of these investigations.

Similar to the rat study discussed before, our results are also not in line with those obtained by Enck et al. ${ }^{3}$. These authors showed a daily rhythm of rectal perception in healthy male volunteers. In rats we evaluated four time points whereas seven were evaluated in the human study. Because of this, variations observed in men may have gone unnoticed in our male Long Evans rats. Further, volunteers were asked to refrain from eating starting at noon and received their first (light) meal at 00:45. Together with possible sleep deprivation (sleeping was allowed between 01:00 and 05:30 only) and continued unnatural conditions for study subjects (rectal balloon catheter remained present during entire timeframe of the study; 26 hours), the abnormal dietary pattern may have influenced study outcome in these healthy volunteers. Importantly, it is also possible that conflicting data arise because diurnal variation in visceral perception is present in healthy men but does not occur in normal Long Evans rats or cannot be properly detected in a robust rat model. Irrespective of these considerations, we have to conclude that in the absence of a circadian rhythm of colonic sensitivity in normal controls, our rat model and methodology are not suitable to investigate disturbed circadian rhythms in relation to visceral hypersensitivity in IBS.

\section{Data availability}

F1000Research: Dataset 1. Excel datasheet showing raw EMG data acquired during colonic distensions, 10.5256/f1000research.7238. d11168922

\section{Author contributions}

$\mathrm{CC}$, AK and RvdW designed research; SB, ZY and OW conducted research; SB, ZY, OW and RvdW analyzed data; SB, ZY and RvdW wrote the paper. All authors read and approved the final manuscript.

\section{Competing interests}

No competing interests were disclosed.

\section{Grant information}

SB was supported by The Netherlands Organization for Health Research and Development (ZonMW), grant number 40-4260098-071 (grant program 'Meer Kennis met Minder Dieren' aiming to publish solid negative data in animal research). ZY was sponsored by the China Exchange Programme of The Royal Netherlands Academy of Arts and Sciences (KNAW, project number 11CDDP005). OW was funded by a grant from the Dutch Organization for Scientific Research (NWO-VIDI).

I confirm that the funders had no role in study design, data collection and analysis, decision to publish, or preparation of the manuscript.
1. Drossman DA, Morris CB, Schneck S, et al.: International survey of patients with IBS: symptom features and their severity, health status, treatments, and risk taking to achieve clinical benefit. J Clin Gastroenterol. 2009; 43(6): 541-550. PubMed Abstract | Publisher Full Text | Free Full Text

2. Keszthelyi D, Troost FJ, Masclee AA: Irritable bowel syndrome: methods, mechanisms, and pathophysiology. Methods to assess visceral hypersensitivity in irritable bowel syndrome. Am J Physiol Gastrointest Liver Physiol. 2012; 303(2): G141-54. PubMed Abstract | Publisher Full Text

3. Enck $\mathrm{P}$, Kaiser $\mathrm{C}$, Felber M, et al:: Circadian variation of rectal sensitivity and gastrointestinal peptides in healthy volunteers. Neurogastroenterol Motil. 2009; 21(1): 52-58.

PubMed Abstract | Publisher Full Text

4. Kalsbeek A, Yi CX, Cailotto C, et al.: Mammalian clock output mechanisms. Essays Biochem. 2011; 49(1): 137-51. PubMed Abstract | Publisher Full Text

5. Manabe N, Tanaka T, Hata J, et al.: Pathophysiology underlying irritable bowe syndrome--from the viewpoint of dysfunction of autonomic nervous system activity. J Smooth Muscle Res. 2009; 45(1): 15-23. PubMed Abstract | Publisher Full Text

6. Chang L, Lee OY, Naliboff B, et al:: Sensation of bloating and visible abdominal distension in patients with irritable bowel syndrome. Am J Gastroenterol. 2001; 96(12): 3341-7.

PubMed Abstract | Publisher Full Text

7. Hoogerwerf WA: Role of biological rhythms in gastrointestinal health and disease. Rev Endocr Metab Disord. 2009; 10(4): 293-300.

PubMed Abstract | Publisher Full Text

8. Nojkov B, Rubenstein JH, Chey WD, et al:: The impact of rotating shift work on the prevalence of irritable bowel syndrome in nurses. Am J Gastroenterol. 2010; 105(4): 842-7.

PubMed Abstract | Publisher Full Text | Free Full Text

9. Barreau F, Ferrier L, Fioramonti J, et al:: New insights in the etiology and pathophysiology of irritable bowel syndrome: contribution of neonatal stress models. Pediatr Res. 2007; 62(3): 240-245.

PubMed Abstract | Publisher Full Text

10. Greenwood-Van Meerveld B, Prusator DK, Johnson AC: Animal models of gastrointestinal and liver diseases. Animal models of visceral pain: pathophysiology, translational relevance, and challenges. Am J Physio pathophysiology, translational relevance, and chal
Gastrointest Liver Physiol. 2015; 308(11): G885-903. PubMed Abstract | Publisher Full Text

11. Gschossmann JM, Buenger $L$, Adam B et al: Diurnal variation of abdominal motor responses to colorectal distension and plasma cortisol levels in rats. Neurogastroenterol Motil. 2001; 13(6): 585-9. PubMed Abstract | Publisher Full Text

12. Welting $\mathrm{O}$, Van Den Wijngaard RM, De Jonge WJ, et al: Assessment of viscera sensitivity using radio telemetry in a rat model of maternal separation. Neurogastroenterol Motil. 2005; 17(6): 838-845. PubMed Abstract | Publisher Full Text

13. Van Den Wijngaard RM, Stanisor OI, van Diest SA, et al.: Peripheral $\alpha$-helical CRF (9-41) does not reverse stress-induced mast cell dependent visceral 
hypersensitivity in maternally separated rats. Neurogastroenterol Motil. 2012; 24(3): 274-82, e111.

PubMed Abstract | Publisher Full Text

14. Stanisor OI, van Diest SA, Yu Z, et al.: Stress-induced visceral hypersensitivity in maternally separated rats can be reversed by peripherally restricted histamine-1-receptor antagonists. PLoS One. 2013; 8(6): e66884. PubMed Abstract | Publisher Full Text | Free Full Text

15. Van Den Wijngaard RM, Stanisor OI, van Diest SA, et al.: Susceptibility to stress induced visceral hypersensitivity in maternally separated rats is transferred across generations. Neurogastroenterol Motil. 2013; 25(12): e780-e790. PubMed Abstract | Publisher Full Text

16. Kramer $\mathrm{K}$, Kinter L, Brockway BP, et al: The use of radiotelemetry in small laboratory animals: recent advances. Contemp Top Lab Anim Sci. 2001; 40(1): 8-16.

PubMed Abstract

17. Mayer EA, Naliboff $B D$, Chang L, et al.: V. Stress and irritable bowel syndrome. Am J Physiol Gastrointest Liver Physiol. 2001; 280(4): G519-G524. PubMed Abstract

18. Moloney RD, O'Mahony SM, Dinan TG, et al:: Stress-induced visceral pain: toward animal models of irritable-bowel syndrome and associated comorbidities. Front Psychiatry. 2015; 6: 15.

PubMed Abstract | Publisher Full Text | Free Full Text

19. Nowland $\mathrm{MH}$, Hugunin $\mathrm{KM}$, Rogers KL: Effects of short-term fasting in male Sprague-Dawley rats. Comp Med. 2011; 61(2): 138-44. PubMed Abstract | Free Full Text

20. O'Malley D, Julio-Pieper M, O'Mahony SM, et al: Differential visceral pain sensitivity and colonic morphology in four common laboratory rat strains. Exp Physiol. 2014; 99(2): 359-67.

PubMed Abstract | Publisher Full Text

21. Kant GJ, Mougey EH, Meyerhoff JL: Diurnal variation in neuroendocrine response to stress in rats: plasma ACTH, beta-endorphin, beta-LPH, corticosterone, prolactin and pituitary cyclic AMP responses. Neuroendocrinology. 1986; 43(3) 383-90.

PubMed Abstract | Publisher Full Text

22. Botschuijver S, Yu Z, Welting O, et al.: Dataset 1 in: Absence of diurnal variation in visceromotor response to colorectal distention in normal Long Evans rats. F1000Research. 2016

Data Source 


\section{Open Peer Review}

\section{Current Peer Review Status:}

\section{Version 1}

Reviewer Report 15 February 2016

https://doi.org/10.5256/f1000research.7798.r12101

(C) 2016 O'Mahony S. This is an open access peer review report distributed under the terms of the Creative Commons Attribution License, which permits unrestricted use, distribution, and reproduction in any medium, provided the original work is properly cited.

\section{Siobhain O'Mahony}

Department of Anatomy and Neuroscience, College of Medicine and Health, University College Cork, Cork, Ireland

Botschuijver et al., present a well written study that is methodologically sound. They assess the diurnal variation (4 timepoints) in visceral sensitivity in Long Evans (male) rats. They also assess the impact of water avoidance stress on visceral sensitivity in maternally separated (male) rats.

I thought it was still worthwhile assessing if there was a diurnal variation in the MS rats. The lack of difference in the control rats should not have deterred them from doing so as there are many studies where changes/differences are seen in man that can never be replicated in rat. Also the authors might want to consider a different strain of rat as different strains may be more responsive to the CRD procedure.

Fig 1D-no error bar on 04:00 hours?

Competing Interests: No competing interests were disclosed.

I confirm that I have read this submission and believe that I have an appropriate level of expertise to confirm that it is of an acceptable scientific standard.

Reviewer Report 04 February 2016

https://doi.org/10.5256/f1000research.7798.r12048

(C) 2016 Quigley E. This is an open access peer review report distributed under the terms of the Creative Commons Attribution License, which permits unrestricted use, distribution, and reproduction in any medium, provided the original work is properly cited.

\section{Eamonn Quigley}


Gastroenterology and Hepatology, The Methodist Hospital, Weill Cornell Medical College, Houston, TX, USA

This study is well done and the results are relatively straightforward. It would have been nice to have control responses on the VMR plots for reference so that one could gauge the magnitude of the response to colo-rectal distension, especially, as this was a novel distension protocol. From a methodological point of view their model is of interest because of its ability to allow the animals to move freely; comparisons with restrained animal results would be interesting.

Competing Interests: No competing interests were disclosed.

I confirm that I have read this submission and believe that I have an appropriate level of expertise to confirm that it is of an acceptable scientific standard.

Reviewer Report 29 January 2016

https://doi.org/10.5256/f1000research.7798.r12045

(C) 2016 Grundy D. This is an open access peer review report distributed under the terms of the Creative Commons Attribution License, which permits unrestricted use, distribution, and reproduction in any medium, provided the original work is properly cited.

\section{David Grundy}

Department of Biomedical Science, University of Sheffield, Sheffield, UK

This is a well conducted study using appropriate methodology providing a clear cut, if negative, data on diurnal variations in visceromotor response to colonic distension. The use of the maternally separated rat model provides validation of the model but raises the question of how diurnal variations may impact on stress induced hypersensitive VMR responses.

Competing Interests: No competing interests were disclosed.

I confirm that I have read this submission and believe that I have an appropriate level of expertise to confirm that it is of an acceptable scientific standard. 
The benefits of publishing with F1000Research:

- Your article is published within days, with no editorial bias

- You can publish traditional articles, null/negative results, case reports, data notes and more

- The peer review process is transparent and collaborative

- Your article is indexed in PubMed after passing peer review

- Dedicated customer support at every stage

For pre-submission enquiries, contact research@f1000.com 